Fecha de recepción: mayo 2014

Fecha de aceptación: mayo 2015

Versión final: julio 2016

\section{Moda y autenticidad histórica en el cine: nuevos ecos de la escuela viscontina}

\author{
Flávio di Cola *
}

Resumen: La obra cinematográfica de Luchino Visconti, en su etapa tardía posterior a la neorrealista -de Senso (1954) a L'innocente (1976), Il gattopardo (1963), La caduta degli dei (1969), Morte a Venezia (1971) y Ludwig (1973) - resaltan de manera tal el papel de los figurines que cualquier producción que involucre evocaciones de la "gran era burguesa" (1850-1914) será rehén de sus reconstituciones filológicas basadas en el trío fisicalidadautenticidad-credibilidad. Este artículo trazará los orígenes de ese legado viscontino y los medios por los cuales la "moda arqueológica" de sus películas es traducida y reproducida en el cine actual.

Palabras clave: arqueología de la moda - costume picture - figurín - historia - Visconti.

[Resúmenes en inglés y portugués en la página 113]

${ }^{(*)}$ Maestría en Comunicaciones y Cultura por la Universidade Federal do Rio de JaneiroECO/UFRJ. Es Publicitario y Profesor de las áreas de Publicidad, Cine y Moda de la Universidade Estácio de Sá, Rio de Janeiro.

\title{
Introducción
}

Una de las características que han marcado más el cine mainstream actual es su tecnificación y-como consecuencia- su propagación tan oportunista como vertiginosa en el paisaje audiovisual contemporáneo asolado por pantallas de todos los tipos y tamaños, a punto de Gilles Lipovetsky y Jean Serroy definen el ambiente cultural que respiramos como una verdadera pantallósfera, caracterizando una sociedad telénica (Lipovetsky, 2009, p. 12). Si la pantalla cinematográfica perdió la hegemonía que ya se detuvo en la construcción del imaginario mundial para otros formatos mucho más fluidos y nómades como desdoblamiento inevitable de una civilización regida por la velocidad, por la dispersión física de las personas y por la urgencia del presente, por otro lado el concepto esencial de "cine" persiste firme como una "promesa de fiesta, catedral del placer de las masas modernas, a través de imágenes y ficciones deslumbrantes” (Ibid, p. 41), cuyos artificios y énfasis en el efecto-imagen buscan un "consumo onírico y fantasmagórico" (Ibid, p. 42).

Y es en la vocación para el encantamiento que Lipovetsky y Serroy encuentran las áreas estructurales comunes al cine y a la moda: el clima de exposición evanescente y de conge- 
lamiento mitológico de las divas asociado a la agitación recreativa, inmediatista y frívola provocada por lo nuevo (Ibid, p. 42). Y en estos tiempos hipermodernos destacadamente paradójicos, el frenesí del presente con sus gratificaciones más evidentes -las novedadesse mantiene al lado del más "amplio movimiento de revivir el pasado" (Goimard, 1969, p. 153). La perpetua hegemonía de la "película histórica" en la lista de las mayores taquillas de la industria audiovisual planetaria -desde la invención del motion picture drama por David Wark Griffith en The birth of a nation (1915) e Intolerance (1916)- es una prueba de que, aunque menospreciado por la crítica intelectualizada, ese género es el "hijo querido de los productores, de los distribuidores y del gran público" 1 .

En ese contexto de prestigio de las reconstituciones históricas cada vez más elaboradas, propiciadas por el efecto-imagen tecnologizado, no es difícil entender el incesante crecimiento de la importancia que la dirección de arte (décor y figurines) ha asumido tanto en la conceptualización, en el planeamiento, en la investigación y en el desarrollo como en la realización, en la pos-realización y en la comercialización de ese tipo de producto audiovisual. Es así que la responsabilidad por el éxito de la lucrativa combinación cine \& historia recae inevitablemente y en gran parte sobre las investigaciones de moda de época, las cuales, muchas veces, motivan la creación de productos y programitas independientes, como comprueba la onda de documentarios del tipo making of.

Sin embargo, el ejemplo fundador supremo de la búsqueda intransigente por la modafigurín o por el figurín-moda auténticos en la película (pues, en este caso, no hay diferencia entre uno y otro, como veremos) sólo podría ser representado por una personalidad artística, y no simplemente por la lógica simplista de la industria del espectáculo. Y esa individualidad se llama Luchino Visconti, el cineasta cuyo proyecto artístico de hacer el pasaje entre los siglos XIX y XX ha inventariado la muerte del primero a través de un desfile crepuscular de la moda de la "gran era burguesa".

\section{La problemática posición de la moda-figurín en la película histórica}

Los estudios sobre la historia de la indumentaria en las primeras décadas del cine mundial son escasos, incluso porque, efectivamente, conocemos muy poco sobre el periodo 1895 1925, que va desde el primer cine hasta el advenimiento del sonido, pues sólo una parte ínfima de las películas producidas en esa época ha sobrevivido incólume y llegado hasta nosotros. Los relatos confiables sobre las rutinas generales de producción de las películas de esa época son raros, y las menciones sobre el vestuario de los actores y actrices aún más escasas. Pero sabemos que los figurines de Lillian Gish para la gran película histórica del período -el ya mencionado The birth of a nation- han sido confeccionados por su propia madre o sacados del ropero personal de mujeres involucradas con el equipo de producción (Landis, 2012, p. 14).

Esa práctica aficionada, por aquel entonces difusa en todo el cine norteamericano, ha sido responsable por raras hibridaciones (Ibid, p. 14) del pasado con el presente en "películas 
históricas". Otro factor de deformación histórica de esas primeras películas -tanto en América como en Europa-fue el fuerte peso de la cultura literaria y teatral popular del siglo XIX que ha irrigado la formación de los primeros artistas de aquel sustento que sería llamado de Séptima Arte, después de mucha reluctancia de los representantes del Alta Cultura.

Sin embargo, en Intolerance-delante de las dimensiones mastodónticas involucradas en la escenificación espectacular de cuatro períodos históricos distintos- Griffith fue obligado a crear estructuras más organizadas para la investigación, diseño y confección de figurines a fin de vestir miles de extras. Esa obra es considerada el germen de la departamentalización de la indumentaria dentro del proceso de industrialización de la película, proceso que se consolidará a lo largo de los años 20, década que inaugura la golden era de las estrellas cinematográficas. El triunfo del star system no trajo inicialmente ninguna o trajo poca visibilidad al ejército de artífices que determinaban el look de los íconos de la pantalla, y los créditos a los figurinistas han permanecido raros. Un aura de sagrado misterio era cultivada alrededor de la estrella, y los artificios por detrás de su éclat debían permanecer ocultos. El advenimiento del cine sonoro traerá un cambio radical en todos los aspectos de esa arte-industria. Al lado de la concentración industrial impuesta por la costosa actualización tecnológica traída por el sonido, el cine mundial fue bañado por un inesperado realismo que influenció poderosamente sus temas, sus recursos expresivos y sus astros. Adrian, el mayor figurinista del mayor estudio de Hollywood (MGM), declaró que "con la llegada del sonido (...) y la entrada de la voz humana, las actrices repentinamente se tornaron seres humanos" (Ibid, p. 19).

Y aquella remota inmortalidad de los "dioses del celuloide" conferida por el centelleo plateado de la pantalla y por el ritual escénico bizantino de las divas -entre las cuales Theda Bara sería el ejemplo más acabado- se precipitó rápidamente en el kitsch y en el olvido. En el interior de esa revolución técnica y de la depresión económica mundial, el figurín cinematográfico fue impelido a acercarse de un modo más realista a la dinámica social de la moda.

Además, con el fin del cine mudo, la "era de los directores" fue súbitamente reemplazada por la "era de los productores", una vez que la llegada y la popularización de la película sonora causaron una profunda reestructuración del negocio cinematográfico en todo el mundo, exigiendo una drástica concentración empresarial. En ese momento, se abulta la figura centralizadora del "productor", eslabón operacional indispensable para dinamizar las nuevas relaciones entre las esferas artística, técnica, industrial, comercial y financiera, frutos de la modernización forzada por los dispositivos tecnológicos de sonido y racionalidad económica. Departamentalización, especialización y subordinación son las nuevas palabras de orden en la organización de los grandes estudios estadounidenses y, en menor grado, en las empresas europeas.

Dos figuras emblemáticas de esa nueva época traducen las transformaciones sufridas por los departamentos de figurines cinematográficos y su sujeción a los dictámenes de la seriación técnico-creativa de una industria que atingía su madurez y apogeo. En 1939, el mismo Adrian escribió lo siguiente para un conjunto de declaraciones sobre la técnica de la película: 
Algunos diseñadores de figurines buscan llenar los ojos. Yo, de mi parte, debo satisfacer al objetivo de la cámara, al ojo penetrante del aparato, instrumento mucho más preciso que nuestra mirada, pues él despoja la imagen del juego de colores y la reduce a un estudio en blanco, negro y gris (Adrian, 1939, p. 70).

En la era de la película, la mirada genial del diseñador-figurinista del gran "momento heroico y sublime" (Lipovetsky, 1989, p. 69) de la primera fase de la historia de la moda moderna -llamado por Lipovetsky moda centenaria (Ibid, p. 69.)- es reemplazado por la de un artífice de efectos gráficos y ópticos. Adrian prosigue:

Como consecuencia, el hilo toma una enorme importancia y sólo las telas de mejor calidad pueden ser empleadas para obtener la perfección en los cortes y en las caídas; o sea, la elaboración debe ser perfecta para que ningún defecto salte a la vista del espectador en los planos cercanos (Adrian, op. Cit., p. 70).

Ese cambio de mirada es literalmente institucionalizado en la más representativa película hollywoodiana de todos los tiempos y, tal vez, de todo el cine-espectáculo -no por casualidad una película histórica: Gone with the wind (1939). Las crónicas registran que su figurinista jefe Walter Plunkett gastó mucha energía en contiendas interminables con el "rey de los productores" de Hollywood y el verdadero "autor" de ese emprendimiento máximo de la industria-arte estadounidense, David O. Selznick. El origen de los conflictos estaba en el melindroso proceso de calibrar con precisión el punto donde la autenticidad histórica de la indumentaria y de la moda en la década de 1860 conseguiría ser asimilada por el gusto y por la cultura del público mundial de cine de los años pre-Segunda Guerra en el contexto de una trama fuertemente romántica (Landis, op. Cit, p. 24) y fotografiada en technicolor. Durante la fase de investigación para la película, Plunkett viajó a Atlanta y con la ayuda de Margaret Mitchell, autora de la novela que dio origen a la película Gone with the wind, localizó piezas auténticas de la indumentaria del período pre-Secesión cuidadosamente guardadas en los baúles de tradicionales familias del sur. De los dobladillos y de otras telas sobrantes de esas reliquias extrajo muestras que, en Hollywood, fueron sometidos a varios tipos de estudios como los de textura, caída, luminosidad o de su efecto en el technicolor, sistema que fotografiaba con tres negativos distintos (rojo, verde y azul) rodando simultáneamente. Durante ese proceso creativo, Plunkett percibió que en la confección de figurines para reconstituciones históricas "no puedes empezar diseñando y después correr detrás de las telas (...). Antes, debes tener en manos muestras de ellas" porque sólo después de experimentarlas "sabrás cómo usarlas". Y compara: “(...) es como construir una casa; tienes que conocer previamente los materiales antes de diseñarla” (Apud Landis, p. 24 y 26).

La película histórica, épica o no, como una de las principales marcas legitimadoras de la hegemonía del concepto de espectáculo cinematográfico estadounidense lo hizo merecedor de las atenciones más extravagantes y costosas que lo ayudaran en la más "noble" y "digna" misión del cine: contar las mayores historias de la humanidad. Ese grandioso -y 
por qué no decir también "enternecedor" (Bragg, 1988, p. 142)- propósito que siempre ha animado a Hollywood desde Griffith, va a encontrar en el director-productor Cecil B. DeMille su versión más pretenciosa y excéntrica.

La actriz Lisa Mitchell, que interpretó el personaje Lulua en el bíblico The Ten Commandments (1956) -“canto del cisne" de DeMille-, narra que sus uñas fueron pintadas con henna por exigencia de los historiadores presentes en el estudio, pues era de esa forma que las beduinas se embellecían. Lisa atestigua que "todo tenía que ser absolutamente auténtico para el sr. De Mille, aunque que mis manos no salieran en close up. Esas uñas tuvieron que recibir la aprobación directa del Sr. De Mille" (Apud DeMille, s/f).

Aunque la preocupación con la investigación esmerada y con las reconstrucciones históricas fieles fuera un punto de honor en Hollywood -siempre alardeada por sus productores y solícitos artesanos- ella se restringía, de verdad, a los escenarios y figurines. Los hechos históricos, en sí, eran atrevidamente alterados o simplificados para adecuarse al tono ufano requerido por el gusto y por la imaginación popular. La galería de deformaciones de carácter fáctico perpetrada no sólo por Hollywood -pero también por cualquier otra industria cinematográfica que haya recurrido a la película histórica para lucrarse o hacerse reconocida- es tan extensa como notoria, y hoy aceptada como natural si considerada en su propia lógica espectacular.

Según el director John Sayles (Carnes, 1997, p. 12), sólo con el florecimiento del fenómeno de la contracultura de los años 1960 es que las películas históricas producidas por la industria audiovisual mainstream pasaron a asimilar las lecciones del revisionismo que asoló a los medios académicos norteamericanos y europeos en fines de los años 1940 y a lo largo de los 1950. Aún de acuerdo con Sayles (Ibid, p.12), la película-síntesis de ese cambio fue Little big man, dirigida por Arthur Penn el 1970, en la fase heroica de la toma de los despojos de la vieja Hollywood por la generación “sexo-drogas-y-rock'n’roll” (Biskind, 2009). Penn profundiza aquí su visión revisionista de las fuerzas históricas que están por detrás de la constitución de la "América profunda" iniciada con Bonnie and Clyde (1969). De esa manera, de la Gran Depresión el fondo histórico se ha trasportado para el Viejo Oeste, donde la cultura cheyenne fue respetuosamente retratada, consagrados héroes de la ocupación anglosajona como el general Custer e Wild Bill Hickok fueron redimensionados, y cuestiones de género y etnia fueron subvertidas a través de un personaje aborigen y... gay. Evidentemente, los efectos más notorios del revisionismo sobre las películas históricas, tales como el relativismo, la descaricaturización y la complejidad también impactaron la forma de concebir los escenarios y los figurines de esas producciones. Con la crisis financiera de fines de los años 1960 avasallando a los estudios estadounidenses y a los grandes productores europeos, el departamento de arte fue uno de los primeros sectores de la industria a tener sus costos drásticamente cortados.

Fue durante ese período de pasaje situado entre el ocaso de la Vieja Hollywood y la consolidación de la Nueva Hollywood por los talentos oriundos de la televisión, del cine experimental o de las escuelas de cine fuertemente influenciadas por el neorrealismo y por la Nouvelle Vague que Edith Head -prototipo de la figurinista de la era de oro de los estudiospercibió que el profesional más importante del departamento de figurín en esas producciones contemporáneas no era más el diseñador creador, sino el shopper-el comprador. 
Esa nueva categoría de "figurinista" estaba, en realidad, sólo respondiendo a las nuevas demandas por economía y autenticidad. Su local de trabajo no consistía más en los cómodos búngalos del wardrobe department de Hollywood o las maisons que vestían a las estrellas europeas, sino en las tiendas de segunda mano, las casas de empeño, los grandes almacenes y los supermercados donde se buscaban las prendas que después irían a influenciar los looks a la vez sencillos y heterodoxos del inicio de los años 1970. Head atestigua: "Cada vez más los figurines de películas contemporáneas son comprados en grandes almacenes en Los Ángeles y Beverly Hills". Ella concluye, puntuando con claridad, que el trabajo del shopper no podría ser comparado, bajo ninguna condición, al de un "artista que tiene su función integrada a una producción cuidadosamente concebida" (Apud Landis, Ibid., p.32). Paradójicamente, el 1970 -auge de la estética naturalista y de los temas sacados de la realidad-se impone a los ojos del público mundial la propuesta aterradora del viaje viscontino al decadentismo belle époque aplastado por la violencia del siglo XX - Muerte a Venecia.

\section{El revisionismo histórico de Visconti: lo arqueológico y la recuperación filológica de la moda}

Muerte a Venecia, adaptación de la novela homónima de Thomas Mann Der Tod in Venedig, fue lanzada en marzo de 1971 con gran alarde y recibida como la obra máxima de Luchino Visconti y como su testamento estético. Se consagró en Cannes, luego enseguida, al llevar un premio especial del jurado en la época (1964-1974) en que fueron suspendidas las codiciadas Palmes d'Or. Para el crítico Freddy Buache, esa película pone cuestiones especialmente caras al universo viscontino y que serán retomadas en Gruppo di familia in un interno (1974): “(...) la creación artística delante de la muerte, el amor, la vejez y la muerte ante la belleza de la juventud y de la vida” (Sanzio \& Thirard, 1984, p. 116.). El propio Visconti afirmó que en Muerte a Venecia materializaba una de sus más viejas aspiraciones, o sea, exponer el tema de la "divergencia que puede surgir entre las aspiraciones estéticas y la vida de un artista, entre su existencia que aparentemente superaría la historia y su propia participación en las condiciones históricas burguesas" (Ibid., p.116).

En ese viaje sin vuelta de Gustav von Aschenbach a la Venecia de 1911, tan bella como pútrida, Visconti suprimió muchos pasajes esencialmente discursivos del texto de Mann que anteceden a la llegada del protagonista a la ciudad de los $d u x$, cambió su profesión de escritor por la de compositor, concentró casi toda la acción en la Venecia moribunda, y -en un rasgo de atrevida infidelidad a la trama original- estableció entre el músico y el efebo Tadzio una delicada reciprocidad amorosa exteriorizada por el contacto visual y por los intercambios largos de miradas que estiran el drama hasta el desenlace fatal. Esas decisiones, aparentemente traidoras de la obra adaptada, en realidad acercaron aún más a Thomas Mann a Luchino Visconti en la misma melancólica observación del inminente derrocamiento de la Alta Burguesía europea y sus ideales. 
La cámara silenciosa y escrutadora de Visconti confirió a Muerte a Venecia una escritura cinematográfica absolutamente inédita, obtenida principalmente por el aprovechamiento de una realidad urbana a la vez específica y atemporal: Venecia, de balneario-pasarela de la flor y nata del grand monde pre-Gran Guerra, se transforma en una trampa dorada, en una metáfora visual del acorralamiento histórico de un mundo preso al pasado, perdida en los laberintos de sus contradicciones y exhausta de su propio ocio contemplativo. El dédalo veneciano de callejones, calles estrechas, puentes, escaleras y la luz crepuscular de la laguna nos conducen inevitablemente a una verdad histórica y violentamente material: el mundo liberal burgués preparó y dará el lugar -después de su extinción-a una onda de indescriptibles horrores, los mismos que poblarán después el drama Gruppo di famiglia in un interno.

Es con Muerte a Venecia que el culto por la credibilidad histórica y por la fisicalidad de lo auténtico como forma de tornar creíbles e irreprensibles las reconstrucciones filológicas del pasado alcanza el paroxismo y se tornará paradigma en las evocaciones ambientales del cine mundial desde entonces. Piero Tosi, figurinista absoluto de Luchino, ya venía trascendiendo de las funciones primarias de la indumentaria-identificar épocas y caracterizar personajes- desde Bellissima (1951). Su mirada refinadísima traspasaba la realidad inmediata y ordinaria simplemente ilustrada por un figurín "correcto" para radiografiar las dimensiones invisibles que cada indumentaria guardaba como potencia, en su arquitectura interna y en su acumulación de detalles imperceptibles que -una vez sumados- revelaban en luz y en texturas la agitación de protagonistas y figurantes en las espectaculares pinturas al fresco novecentistas de la historia italiana en películas como Senso (1954) e Il gattopardo (1963).

Sin embargo, en la gran aventura visconti-manniana de 1971, Tosi asume también la función de "arqueólogo de la moda", encargado de materializar el ideal viscontino de verdad absoluta -física e histórica- de los figurines y sus materiales (Vallora, 2009, p. 41), cuyo ápice es la utilización de una gran cantidad de ropas auténticas de la belle époque a lo largo de toda la película, hazaña solamente posible en el contexto de la compleja tradición artística italiana con sus sartorie de figurines y aderezos, como la ya extinta SAFAS Costumi Teatrali, de Milano, y el todavía muy solicitado Atelier Tirelli, de Roma, con su incomparable colección de indumentarias vintage reunidas a lo largo de décadas por el trabajo pionero de Umberto Tirelli y transformadas en referencias para investigaciones en proyectos cinematográficos que ambicionen preservar y actualizar el legado visconti-tosiano. Más que un legado, una visión que abolió los límites entre figurín y moda.

Es verdad que Walter Plunkett, en la Hollywood de los años 1930, también peregrinó como un ávido arqueólogo en búsqueda de lo auténtico con el objetivo no sólo de apropiarse de su "aura", pero también de reproducirla en laboratorio y traducirla en technicolor a través de la expertise artístico-tecnológica de los estudios. Pero ese deseo se subordinaba a un proyecto de calificación absoluta e indisputable del espectáculo hollywoodiano conducido por algunos productores visionarios encargados de la tercera mayor industria estadounidense en franca lucha por la hegemonía en la conturbada arena ideológica global, en la cual se oponían la solitaria democracia liberal estadounidense y la emergente fascinación totalitaria a la izquierda y a la derecha. 
El deseo de Luchino Visconti fue más bien otro: al sorprender a sus personajes afectados por un cierto momento de la historia -la construcción de la Italia moderna-, él nos recuerda que la existencia humana es totalmente determinada por las condiciones históricas que la rodean. Es en ese espacio material que sus personajes se debaten desesperadamente en el intento de auto-determinarse entre "las cosas y-sobre todo contra ellas" (Sanzio, op. Cit., p. 26). En resumen, las obras viscontinas, sean las escenificadas en el pasado o en el presente, abordan básicamente "la libertad humana contra el orden social".

La obsesión de Visconti por la exactitud y por lo auténtico en las reconstrucciones históricas -hasta hoy objeto de muchos chistes deliciosos- no se justifica, por lo tanto, sólo por su fondo estético o por los hechos reales que atraviesan la línea dramática de sus personajes. Para el cineasta, escenarios y figurines filológicamente fieles son indispensables para situar y encuadrar históricamente a sus héroes, y también para explicar por qué hacen esa o aquella elección. Como Visconti mismo declaró:

Los personajes de mis películas acaban por encontrarse frente a sí mismos. La protección que pueda venir del amor o de la familia les falta, los privilegios propiciados por el poder o el dinero no son suficientes para protegerlos. Ellos están solos." (Visconti, apud Sanzio op. Cit., p. 27).

Y es en esos momentos tan fugaces como fundamentales que la recuperación arqueológica de la moda a través del figurín ayuda a puntuar la condición tan solitaria como indefensa del hombre ante las fuerzas de la historia.

El poder imaginario y evocador de la indumentaria filológicamente reconstruida y perpetuada por la escuela visconti-tosiana y ejecutada por la noble tradición de las sartorie italianas no murió y continúa inspirando poderosamente el cine actual. Los grandiosos "edificios históricos" cinematográficamente elaborados por Zeffirelli, Coppola, Scorsese, Kubrick, Malick, Polansky, Bertolucci, Hudson, Bergman (en Fanny och Alexander), Leone, Ivory, Minghella, Cameron, Lee, Wright, Gilliam, Burton -entre otros cineastas definidores del cine contemporáneo- le serán tributarios, mientras los figurinistas herederos y renovadores de esa tradición -como Milena Canonero, Gabriella Pescucci, Maurizio Millenotti, Vera Marzot, Massimo Parrini, Franco Carretti, Nicoletta Ercole, Carlo Poggioli, entre otros- continúen a hacernos ver el carácter invisible de la historia.

\section{Notas}

1. En la lista de los nueve nominados a los Academy Awards (Oscar) del 2013, cinco de ellos pueden ser clasificados como "películas históricas" o como revisiones de la historia reciente: Lincoln, Zero Dark Thirty, Les Misérables, Django Unchained y Argo, y todos obtuvieron en sus lanzamientos espectaculares resultados en las taquillas nacional e internacional. Ese fenómeno también se extiende a las tv series a través de títulos recientes como The Tudors, The Pillar of the Earth, Roma, The Borgias y Downton Abbey, que se incluyen entre los mayores éxitos de la emisoras del mundo entero. 


\section{Referencias Bibliográficas}

Adrian. (1939). Les costumes. In: Watts, S. (org.). La technique du film par 16 artistes et spécialistes de Hollywood. Paris: Payot, p. 70. [Traducción libre del autor.]

Biskind, P. (2009). Como a geração sexo-drogas-e-rock'n'roll salvou Hollywood: Easy Riders, Raging Bulls. Rio de Janeiro: Intrínseca.

Bragg, M. (1988). Rich: a vida fascinante de Richard Burton. São Paulo: Best Seller, p. 142.

Carnes, M. C. (1997). Passado imperfeito: a história no cinema. Rio de Janeiro: Record, p. 12.

DeMille, C. B. (s/f). Os dez mandamentos. [DVD] Paramount. Disco 2: Extras y Dados Técnicos. Manaus: Videolar.

Goimard, J. (1969). O filme histórico: um agonizante caluniado. In: Cinema Americano: 1960-1968. Coleção Cadernos de Cinema. Lisboa: Publicações Dom Quixote, p. 153.

Landis, D. N. (2012). A short history of Hollywood costume design 1912-2012. In: Hollywood Costume. Londres: V\&A Publishing, pp. 14, 19, 24, 26, 32.

Lipovetsky, G. (2009). A tela global: mídias culturais e cinema na era hipermoderna. Porto Alegre: Sulina, pp. 12, 41-42.

(1989). O império do efêmero: a moda e seu destino nas sociedades modernas. São Paulo: Companhia das Letras, p. 69.

Sanzio, A. \& Thirard, P-L. (1984). Luchino Visconti cinéaste. Paris: Éditions Persona/Ramsay Poche Cinéma, pp. 26, 27, 116.

Vallora, M. (2009). Pizzi, gale, share e scale mercalli. In: L'atelier degli Oscar: i costumi della sartoria Tirelli per il grande cinema. Gorizia: Musei Provinciali, p. 41.

Summary: The film work of Luchino Visconti in its late stage subsequent to the neorealist one-from Senso (1954), L'innocente (1976), Il Gattopardo (1963), La caduta degli dei (1969), Morte a Venezia (1971) and Ludwig (1973) - so highlight the role of fashion plates that any production involving evocations of the "big bourgeois era" (1850-1914) will be held hostage to his philological reconstructions based on the threesome physicality-authenticity-credibility. This article will trace the origins of this Visconti legacy and the means by which the "archaeological fashion" of his films is translated and reproduced in contemporary cinema.

Keywords: costume picture - fashion archeology - fashion plate - history - Visconti.

Resumo: A obra cinematográfica de Luchino Visconti, especificamente a tardia que sucede à neo-realista -de Senso (1954) a L'innocente (1976), passando por Il gattopardo (1963), La caduta degli dei (1969), Morte a Venezia (1971) e Ludwig (1973)- remarcou o papel dos figurinos de tal modo que qualquer produção mainstream que envolva evocações da "grande era burguesa" (1850-1914) será refém, até hoje, de suas reconstituições filológicas baseadas no trio fisicalidade-autenticidade-credibilidade. Este artigo traçará as origens desse legado viscontino e os meios pelos quais a moda arqueológica de seus filmes é traduzida e reproduzida no cinema atual.

Palavras chave: arqueologia da moda - costume picture - figurino - história - Visconti. 